\title{
CHARACTERIZATION OF CORONAVIRUS DI RNA PACKAGING
}

\author{
K. H. Kim, K. Narayanan, and S. Makino \\ Department of Microbiology, and Institute of Cellular and Molecular Biology \\ The University of Texas at Austin \\ Austin, Texas 78712
}

\begin{abstract}
Studies of defective interfering (DI) RNAs of mouse hepatitis virus (MHV), suggest that a $69 \mathrm{nt}$-long packaging signal, which is located about $20 \mathrm{~kb}$ from the 5 '-end of the 31 kb-long MHV genomic RNA, is necessary and sufficient for MHV genomic RNA packaging into MHV particles. We demonstrated that use of a low $\mathrm{pH}$ culture medium combined with subsequent ultrafiltration increased MHV infectivity about 60 times over MHV preparations grown in neutral medium. Using this virus concentration procedure, we successfully prepared DI particle-rich MHV preparations. Characterization of virus samples released from the cells infected with DI particle-rich MHV revealed that infectious MHV genomic RNA was not required for packaging of DI RNAs. These data suggested that interaction of the DI packaging signal with an unidentified region(s) of helper virus genomic RNA is unlikely, and therefore unlikely to facilitate the packaging of MHV DI RNA into the MHV virion. Rather, both DI RNA and MHV genomic RNA probably use the packaging signal for RNA packaging.
\end{abstract}

\section{INTRODUCTION}

Mouse hepatitis virus (MHV), contains three envelope proteins, $\mathrm{S}, \mathrm{M}$, and $\mathrm{E}$ proteins and an internal $\mathrm{N}$ protein. $\mathrm{N}$ protein and a $31 \mathrm{~kb}$-long MHV genomic RNA (Lee et al.., 1991; Pachuk et al., 1989) form a helical nucleocapsid (Macnaughton et al., 1978). M protein and E protein are both necessary for packaging of viral nucleocapsid (Kim et al., 1997) and MHV assembly (Kim et al., 1997; Vennema et al., 1996; Bos et al., 1996), while S protein is dispensable for both (Kim et al., 1997; Vennema et al., 1996; Bos et al., 1996). Of the 7-8 species of MHV mRNAs, which consist of a 3' coterminal nested-set 
structure, only mRNA 1 is packaged into MHV virions (Lai and Stohlman, 1978), indicating that there is a mechanism which allows specific packaging of mRNA 1 into MHV.

Studies of cloned defective interfering (DI) RNAs of MHV identified an MHV RNA signal (packaging signal) that is necessary for MHV DI RNA packaging into MHV particles (Fosmire et al., 1992). The 69 nt-long packaging signal is sufficient for RNA packaging into MHV particles (Woo et al., 1997). This packaging signal resides about $20 \mathrm{~kb}$ from the 5'-end of the MHV genome (Fosmire et al., 1992), and presumably is necessary for packaging of MHV mRNA 1 into MHV particles.

MHV DI particles are not separable from infectious MHV particles by sucrose gradient centrifugation (Fosmire et al., 1992; Makino et al., 1990), therefore, whether or not MHV genomic RNA is required for packaging of MHV DI RNAs into MHV particles is not known. If MHV genomic RNA is always required for packaging of DI RNAs, there is a possibility that the packaging signal in DI RNAs is not a signal for MHV genomic RNA, but is a signal that interacts with the helper virus genomic RNA; DI RNAs may "piggyback" MHV genomic RNA and be packaged into MHV particles. If this is the case, then the mechanism of MHV genomic RNA packaging should differ from that of DI RNA packaging; the identified 69-nt-long packaging signal should be necessary only for packaging of MHV DI RNAs, but not for packaging of MHV genomic RNA. If copackaging of MHV genomic RNA is not always necessary for DI RNA packaging, then the identified packaging signal is most likely one of the elements that is required for MHV RNA packaging.

To further understand the mechanism of coronavirus RNA packaging, we asked whether MHV genomic RNA is required for packaging of DI RNAs into virions. To address this question, we first needed to establish a procedure which significantly increases MHV infectivity. Our study demonstrated that copackaging of genomic RNA with MHV DI RNA was not required for MHV DI RNA packaging.

\section{MATERIALS AND METHODS}

\section{Viruses and Cells}

Plaque-cloned MHV-A59 was used as a helper virus. Mouse DBT cells (Hirano et al., 1974) were used for MHV growth.

\section{Concentration of MHV}

For ammonium sulfate precipitation, MHV-infected DBT cell culture fluid was brought to $50 \%$ saturation by ammonium sulfate followed by centrifugation at $8,000 \mathrm{rpm}$ for 30 min using a Beckman JA-14 rotor. Virus was suspended in NTE buffer $(0.1 \mathrm{M}$ $\mathrm{NaCl}, 0.01 \mathrm{M}$ Tris- $\mathrm{HCl}, \mathrm{pH} 7.2$, and $0.001 \mathrm{M}$ EDTA) at $1 / 10-1 / 20$ of the original volume and transferred into two different dialysis membranes, one with a molecular weight cut off of $10 \mathrm{kDa}$ (MWCO $10 \mathrm{k}$ membrane) and the other with a molecular weight cut off of 500 $\mathrm{kDa}$ (MWCO $500 \mathrm{k}$ membrane). The virus suspension was then dialyzed against 1.5 liters of phosphate buffered saline (PBS) at $4^{\circ} \mathrm{C}$ for overnight. To the dialysate, we added kanamycin to a final concentration of $1 \mathrm{mg} / \mathrm{ml}$ and fetal calf serum to $2 \%$ and stored the samples at $-80^{\circ} \mathrm{C}$. For volume concentration by powdered polyethylene glycol 8000 (PEG), the culture fluid was transferred into either a $10 \mathrm{k}$ molecular weight cutoff (MWCO) membrane or a $500 \mathrm{k}$ MWCO membrane, and both membranes were buried in 
PEG powder and placed at $0^{\circ} \mathrm{C}$ for $3-5 \mathrm{~h}$. The volume of culture fluid was reduced through adsorption of water by the PEG powder. Once the total volume decreased to about $1 / 10-1 / 20$ of the original volume, the virus samples were dialyzed against PBS and stored as described above. We used centricon 100 (Amicon) for ultrafiltration. Virus samples were placed into the top chamber of a centricon 100 unit, and centrifuged at 3,000 rpm using a Beckman JA-14 rotor. After $1 \mathrm{~h}$ of centrifugation, the volumes of the virus samples were reduced to about $1 / 20$ th of the original volume. Concentrated virus samples were then stored at $-80^{\circ} \mathrm{C}$.

\section{RNA Transcription and Transfection}

MHV DI cDNA FAl (Fosmire et al., 1992) was linearized by Xba I digestion and RNA was synthesized in vitro as previously described (Makino and Lai, 1989). The lipofection method was used for RNA transfection as previously described (Felgner $e t$ al., 1987).

\section{Purification of MHV}

MHV particles were purified by sucrose gradient centrifugation as described previously (Kim et al., 1997).

\section{Preparation and Characterization of Virion RNA and Intracellular RNAs}

Synthesis of virus-specific RNAs was examined by labeling of virus RNA with ${ }^{32} \mathrm{P}$ orthophosphate in the presence of $2.5 \mu \mathrm{g} / \mathrm{ml}$ actinomycin $\mathrm{D}$ for $2 \mathrm{~h}$ from 5 to $7 \mathrm{~h}$ postinfection (p.i.). Virion RNA and the intracellular RNA was extracted (Makino et al., 1984) and analyzed by agarose gel electrophoresis (McMaster and Carmichael, 1977). Northern blot analysis was performed as described previously (Makino et al., 1991). A $1 \mathrm{~kb}$-long Stu I-Spe I fragment that corresponds to the $0.5-1.5 \mathrm{~kb}$ region from the 5' end of MHV DIssF clone, DF1-2 (Makino et al., 1990), was used as a probe.

\section{RESULTS}

If MHV genomic RNA is always required for DI RNA packaging, a reasonable amount of MHV genomic RNAs should be detected in DI virion RNA preparations. If copackaging of MHV genomic RNA is not required for DI RNA packaging, then the amount of MHV genomic RNA may be very minute in the DI particle-rich virus preparations. To examine whether the presence of MHV genomic RNA in virus particles was required for DI RNA packaging, we needed to prepare DI particle-rich MHV samples, in which most of the viruses were DI particles. Generally, virus samples containing large amounts of MHV DI particles were prepared from cell cultures in which most of cells were coinfected with DI particles and infectious helper virus. We attempted to enhance the concentration of DI particles by using various procedures that may increase infectivities of MHV.

We first tested the effect of culture medium $\mathrm{pH}$ on MHV replication, because some coronaviruses grow to higher titers in culture media with low $\mathrm{pH}$ than in neutral $\mathrm{pH}$ media (Alexander and Collins, 1975; Pocock and Garwes, 1975). In agreement with this, we found that MHV grew to a higher titer using the low $\mathrm{pH}(\mathrm{pH}$ 6.0) medium than the neutral 


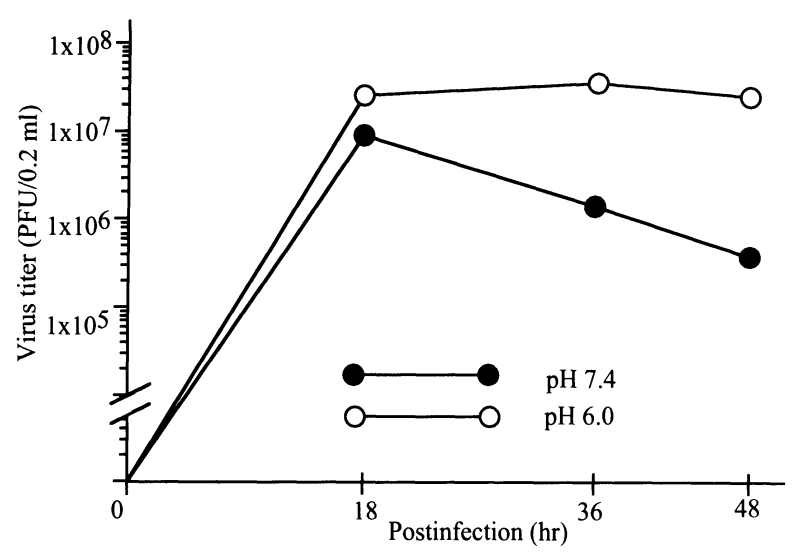

Figure 1. Growth of MHV in the neutral $\mathrm{pH}$ medium and low $\mathrm{pH}$ medium. DBT cells were infected with MHV at a multiplicity of infection (m.o.i.) of 5 , and incubated with the neutral $\mathrm{pH}$ medium (black circles) or the low $\mathrm{pH}$ medium (open circles). Culture fluids were harvested at p.i., $18 \mathrm{~h}, 36 \mathrm{~h}$ and $48 \mathrm{~h}$ and virus infectivities were examined by plaque assay.

$\mathrm{pH}$ (pH 7.4) medium (Fig. 1). We then tested three different procedures for concentrating MHV. Ammonium sulfate precipitation, concentration by PEG powder, and ultrafiltration all increased MHV infectivity, however, ultrafiltration consistently showed excellent enhancement of infectivity and specific infectivity (Table 1). Enhancement of infectivity when using ammonium sulfate precipitation and PEG concentration was about half to two thirds that of the ultrafiltration procedure (data not shown). Inhibition of MHV RNA synthesis did not occur in the cells that were infected with MHV concentrated by ultrafiltration (Fig. 2A). MHV RNAs accumulated efficiently in the cells infected with MHV grown in the low pH medium (Fig. 2B). Although viral RNA was efficiently produced in the neutral $\mathrm{pH}$ cells at $18 \mathrm{~h} \mathrm{p}$.i., it was significantly lower at $36 \mathrm{~h}$ p.i. (Fig. 2B, lanes 3,4 ); this lower level of MHV RNA synthesis at $36 \mathrm{~h}$ p.i. was not so obvious in the MHV samples

Table 1. Enhancement of MHV infectivities after concentration of viruses by using ultrafiltration

\begin{tabular}{lcccc}
\hline Concentration methods & $\begin{array}{c}\text { MHV titer } \\
\text { PFU/0.2 ml }\end{array}$ & $\begin{array}{c}\text { Volume } \\
\text { reduction (VR) }\end{array}$ & $\begin{array}{c}\text { Enhancement of } \\
\text { infectivity (EI) }\end{array}$ & $\begin{array}{c}\text { Specific infectivity } \\
(\text { VR } \times \text { EI) }\end{array}$ \\
\hline Exp. 1 & & & & \\
$\quad$ No concentration & $1.5 \times 10^{6}$ & & & \\
$\quad$ After concentration & $2.3 \times 10^{7}$ & $1 / 20$ & 15.3 & 0.77 \\
Exp. 2 & $4.3 \times 10^{6}$ & & & \\
$\quad$ No concentration & $3.2 \times 10^{7}$ & $1 / 20$ & 7.4 & 0.37 \\
$\quad$ After concentration & & & & \\
Exp. 3 & $5.0 \times 10^{5}$ & & & 0.44 \\
$\quad$ No concentration & $4.4 \times 10^{6}$ & $1 / 20$ & 8.8 & \\
$\quad$ After concentration &
\end{tabular}

${ }^{\mathrm{a}}$ Final volume of virus samples after dialysis or ultrafiltration.

${ }^{b}$ Fold increase of MHV infectivities after concentration/dialysis or ultrafiltration as compared with MHV infectivities in culture fluid. 


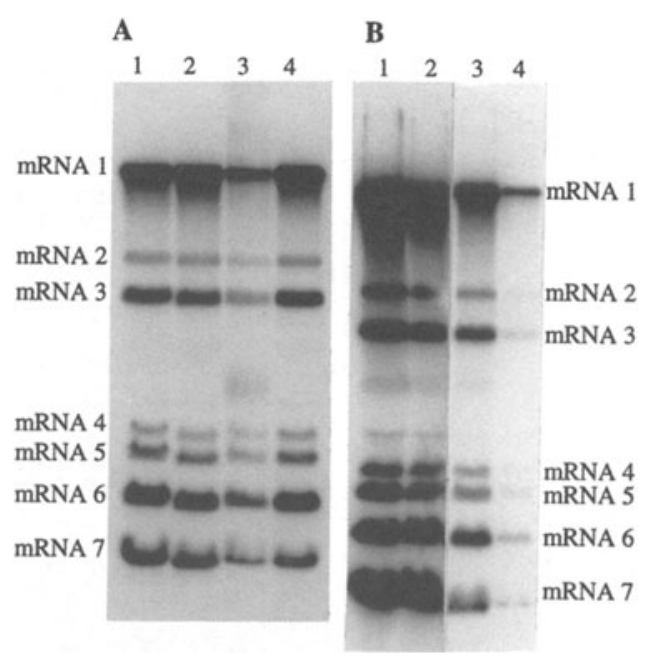

Figure 2. Synthesis of MHV-specific intracellular RNAs. (A) MHV samples that were concentrated by ultrafiltration were used as inoculum. Lanes 1 and 3 show MHV-specific intracellular RNAs after infection of untreated virus samples. Lanes 2 and 4 show MHV-specific intracellular RNAs after infection of concentrated virus (Centricon 100) samples. The m.o.i. of inoculum were 1, 15, 0.3 and 3 for lanes $1,2,3$ and 4 respectively. (B) MHV-specific intracellular RNA synthesis after infection of MHV samples that were grown in the low $\mathrm{pH}(\mathrm{pH}$ 6.0) medium (lanes 1,2) or the neutral $\mathrm{pH}(\mathrm{pH} 7.4)$ medium (lanes 3, 4). The m.o.i. of inoculum were 17, 23,6 and 1 for lanes 1, 2, 3 and 4 respectively. RNA was extracted at $18 \mathrm{~h}$ p.i. for lanes 1 and 3 , and $36 \mathrm{~h}$ p.i. for lanes 2 and 4. All MHV samples were inoculated without dilution. Species and location of seven MHV mRNAs are shown by mRNA 1 -mRNA 7.

grown in the low pH medium (Fig. 2B, lanes 1,2). To obtain MHV with the highest infectivity, we combined these two procedures. MHV-infected DBT cells were incubated in the low $\mathrm{pH}$ medium or neutral $\mathrm{pH}$ medium and harvested at $18 \mathrm{~h}$ p.i. The culture fluid from the low $\mathrm{pH}$ medium was concentrated by ultrafiltration. Plaque assay analysis showed that MHV released into the neutral $\mathrm{pH}$ medium had a titer of $3.5 \times 10^{6} \mathrm{PFU} / 0.2 \mathrm{ml}$, while the virus sample isolated after growth in cells cultured in the low $\mathrm{pH}$ medium followed by 20 fold ultrafiltration concentration yielded $2.2 \times 10^{8} \mathrm{PFU} / 0.2 \mathrm{ml}$. Combination of the two procedures increased MHV infectivity about 60 times.

FA1 DI RNA (Fosmire et al., 1992), which contains the packaging signal, was synthesized in vitro and transfected into MHV-infected cells. Cells were grown in the low $\mathrm{pH}$ medium and the culture fluid was collected after overnight incubation. DBT cells were infected with this virus sample or virus samples that were concentrated by using ultrafiltration. Cells were cultured for $12 \mathrm{~h}$ in the presence of ${ }^{32} \mathrm{Pi}$. Agarose gel electrophoresis of ${ }^{32} \mathrm{P}$-labeled virion RNAs extracted from purified MHV particles showed that the majority of virion RNAs were DI RNAs (Fig. 3, lane 2). Only a trace amount of infectious virus genomic RNA was found in the virus sample containing FA1 DI particles, whereas a large amount of infectious virus genomic RNA was present in the helper virus preparation (Fig. 3, lane 1). If unconcentrated inoculum was used, we detected a higher amount of genomic RNA in some experiments (data not shown), while virus samples obtained from the cells infected with concentrated virus sample consistently showed the presence of a m- 


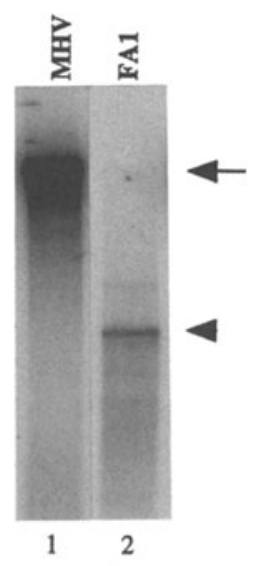

Figure 3. Agarose gel electrophoresis of ${ }^{32} \mathrm{P}$-labeled virion RNA extracted from purified virus particles. ${ }^{32} \mathrm{P}$-labeled MHVs were purified from cells infected with MHVA59 (lane 1) or from cells infected with MHV-A59 containing FA1 DI particles (lane 2). Extracted virion RNAs were separated by $1 \%$ agarose-formaldehyde gel electrophoresis. Arrow indicates MHV-A59 genomic RNA. Arrowhead indicates FA1 DI RNA.

inute amount of helper virus genomic RNA (data not shown). Densitometric analysis of the autoradiogram showed that the molar ratio of helper virus genomic RNA to FA1 DI RNA was approximately 1 to 1,000 . If packaging of MHV DI RNAs requires the presence of at least one infectious virus genomic RNA in a virion, then this data would have indicated that each MHV DI particle must contain, on average, one infectious genomic RNA plus 1,000 DI RNA molecules. However, the buoyant density of DI particles and that of helper virus is the same (Fosmire et al., 1992; Makino et al., 1990). It is highly unlikely that MHV particles that contained one infectious genomic RNA molecule plus 1,000 DI RNA molecules had the same density as infectious MHV. These data indicated not only that most DI RNA molecules were packaged into MHV virion in the absence of the infectious virus genome, but also that most DI particles contained only DI RNAs. Therefore, the possibility that the packaging signal in DI RNAs is a signal that interacts with the helper virus genomic RNA is highly unlikely. Packaging of MHV DI RNA and MHV genomic RNA probably underwent the same mechanism.

\section{DISCUSSION}

In the present study we found that the combination of ultrafiltration and low $\mathrm{pH}$ culture medium significantly increased MHV infectivity. This concentration procedure will be useful for the preparation of MHV samples with high infectivity.

The data shown in Fig. 3 indicated that MHV DI particles contained mostly DI RNAs; if DI particles that contain MHV genomic RNA exist at all, they exist only as a very minor population. That the packaging signal of DI RNA interacts with an unidentified region(s) of helper virus genomic RNA, and that such an interaction facilitates the packaging of MHV DI RNA into the virion is less likely than the possibility that both DI RNA and MHV genomic RNA probably use the packaging signal for RNA packaging. The data shown in this study was consistent with the observation that the kinetics of intracellular DI RNA synthesis after infection of the serially diluted DI particle-containing MHV preparation follows two hit-kinetics, while kinetics of helper virus mRNA synthesis follows one-hit kinetics based on virus dilution experiments (Makino et al., 1988). We ob- 
tained a similar result using the efficiently packaged DI RNA, DIssF (Makino, unpublished data). If DI RNAs were always copackaged with helper virus genomic RNA, then DI RNA and helper virus genomic RNA should be cointroduced into host cells, and the virus dilution experiment would have resulted in one-hit kinetics of DI RNA.

\section{ACKNOWLEDGMENTS}

This work was supported by Public Health Service grants AI29984 and AI32591 from the National Institutes of Health.

\section{REFERENCES}

Alexander, D.J., and Collins, M.S., 1975, Effect of $\mathrm{pH}$ on the growth and cytopathogenicity of avian infectious bronchitis virus in chicken kidney cells, Arch. Virol. 49:339-348.

Bos, E.C.W., Luytjes, W., van der Muelen, H., Koerten, H.K., and Spaan, W.J.M., 1996, The production of recombinant infectious DI-particles of a murine coronavirus in the absence of helper virus, Virology 218:52-60.

Felgner, P.L., Gadek, T.R., Holm, M., Roman, R., Chan, H.W., Wenz, M., Northrop, J.P., Ringgold, G.M., and Danielson, M., 1987, Lipofection: a high efficient, lipid- mediated DNA-transfection procedure, Proc. Natl. Acad. Sci. USA 84:7413-7417.

Fosmire, J.A., Hwang, K., and Makino, S., 1992, Identification and characterization of a coronavirus packaging signal, J.Virol. 66:3522-3530.

Hirano, N., Fujiwara, K., Hino, S., and Matsumoto, M., 1974, Replication and plaque formation of mouse hepatitis virus (MHV-2) in mouse cell line DBT culture, Arch. Gesamte. Virusforch. 44:298-302.

Kim, K.H., Narayanan, K., and Makino, S., 1997, Assembled coronavirus from complementation of two defective interfering RNAs, J.Virol. 71:3922-3931.

Lai, M.M.C., and Stohlman, S.A., 1978, RNA of mouse hepatitis virus, J.Virol. 26:236- 242.

Lee, H.-J., Shieh, C.-K., Gorbalenya, A.E., Eugene, E.V., La Monica, N., Tuler, J., Bagdzhadzhyan, A., and Lai, M.M.C., 1991, The complete sequence (22 kilobases) of murine coronavirus gene 1 encoding the putative proteases and RNA polymerase, Virology 180:567-582.

Macnaughton, M.R., Davies, H.A., and Nermut, M.V., 1978, Ribonucleoprotein-like structures from coronavirus particles, J.Gen.Virol. 39:545-549.

Makino, S., unpublished data.

Makino, S., and Lai, M.M.C., 1989, High-frequency leader sequence switching during coronavirus defective interfering RNA replication, J.Virol. 63:5285-5292.

Makino, S., Taguchi, F., Hirano, N., and Fujiwara, K., 1984, Analysis of genomic and intracellular viral RNAs of small plaque mutants of mouse hepatitis virus, JHM strain, Virology 139:138-151.

Makino, S., Shieh, C.-K., Keck, J.G., and Lai, M.M.C., 1988, Defective-interfering particles of murine coronavirus: mechanism of synthesis of defective viral RNAs, Virology 163:104-111.

Makino, S., Yokomori, K., and Lai, M.M.C., 1990, Analysis of efficiently packaged defective interfering RNAs of murine coronavirus: localization of a possible RNA- packaging signal, J.Virol. 64:6045-6053.

Makino, S., Joo, M., and Makino, J.K., 1991, A system for study of coronavirus mRNA synthesis: a regulated, expressed subgenomic defective interfering RNA results from intergenic site insertion, J.Virol. 65:6031-6041.

McMaster, G.K., and Carmichael, G.G., 1977, Analysis of single- and double-stranded nucleic acids on polyacrylamide and agarose gels by using glyoxal and acridine orange, Proc. Natl. Acad. Sci. USA 74:4835-4838.

Pachuk, C.J., Bredenbeek, P.J., Zoltick, P.W., Spaan, W.J.M., and Weiss, S.R., 1989, Molecular cloning of the gene encoding the putative polymerase of mouse hepatitis virus, strain A59, Virology 171:141-148.

Pocock, D.H., and Garwes, D.J., 1975, The influence of pH on the growth and stability of transmissible gastroenteritis virus in vitro, Arch. Virol. 49:239-247.

Vennema, H., Godeke, G.-J., Rossen, J.W.A., Voorhout, W.F., Horzinek, M.C., Opstelten, D.-J.E., and Rottier, P.J.M., 1996, Nucleocapsid-independent assembly of coronavirus-like particles by co-expression of viral envelope protein genes, EMBOJ. 15:2020-2028.

Woo, K., Joo, M., Narayanan, K., Kim, K.H., and Makino, S., 1997, Murine coronavirus packaging signal confers packaging to nonviral RNA, J.Virol. 71:824-827. 